\title{
Evolution and stability of texture during thermomechanical processing of Ti-24Al-11Nb alloy
}

\author{
SATYAM SUWAS and R K RAY* \\ Department of Materials and Metallurgical Engineering, Indian Institute of Technology, Kanpur 208 016, India
}

\begin{abstract}
The evolution of basal texture during thermomechanical processing of $\mathrm{Ti}-24 \mathrm{Al}-11 \mathrm{Nb}$ alloy has been studied as a function of different processing variables like hot rolling temperature, amount of deformation, cooling conditions etc. The stability of the deformation texture during post-rolling annealing and during the $\alpha_{2} \rightarrow \beta \rightarrow \alpha_{2}$ phase transformation cycle was also investigated. Unrestricted rolling of primary $\alpha_{2}$ to maximum thickness reduction at the lowest rolling temperature has been found to be most favourable for obtaining a good basal texture. Texture of transformed (secondary) $\alpha_{2}$ is generally non basal when the transformation takes place from deformed $\beta$. Rolling texture does not seem to change during annealing leading to recrystallization. The $\alpha_{2} \rightarrow \beta \rightarrow \alpha_{2}$ phase transformation cycle does not change the starting basal texture and a starting non basal texture also does not give rise to basal texture due to this treatment.
\end{abstract}

Keywords. Rolling texture; recrystallization texture; textural stability; Ti-24AL-11Nb

\section{Introduction}

The need for developing materials with enhanced engine performance through lighter weights and higher operating temperatures spurred research interest on $\mathrm{Ti}_{3} \mathrm{Al}$ and its derivatives. However, this material suffers from a severe limitation due to complete absence of room temperature plasticity. Niobium addition has emerged as the most successful means for overcoming this drawback. Addition of $\mathrm{Nb}$ to $\mathrm{Ti}_{3} \mathrm{Al}\left(\alpha_{2}\right)$ stabilizes the b.c.c. $(\beta)$ phase of titanium even at room temperature and thereby strength, toughness and ductility all increase. The first $\mathrm{Ti}_{3} \mathrm{Al}$ based composition which demonstrated satisfactory room temperature ductility has been reported to be Ti-24Al$11 \mathrm{Nb}$ (in at\%). Since then a number of studies have been carried out with a view to exploiting the full potential of this material. As the application of Ti-24Al$11 \mathrm{Nb}$ or any other $\mathrm{Nb}$ modified $\mathrm{Ti}_{3} \mathrm{Al}$ base alloy requires the material mostly in sheet form, several attempts have been made to study the deformation processing of this material. Since it is not suitable for room temperature rolling, elevated temperature working with or without a post annealing treatment is usually recommended. Although quite a few papers have been published on the processing of $\mathrm{Ti}_{3} \mathrm{Al}-\mathrm{Nb}$ alloys and $\mathrm{Ti}-24 \mathrm{Al}-11 \mathrm{Nb}$ alloy in particular, the issue of textures which is likely to be of extreme importance for such h.c.p. structured materials with regard to mechanical properties, has not at all been paid serious attention (Banerjee 1994). It has also been established that h.c.p. Ti alloys, composed mainly of basal-textured $\alpha$ grains, exhibit significant

*Author for correspondence improvement in ductility which ultimately decides the sheet formability characteristics of the material. An attempt has therefore been made to explore various possibilities for the production of basal texture in thermomechanically processed $\mathrm{Ti}-24 \mathrm{Al}-11 \mathrm{Nb}$ alloy sheets. In addition, the stability of basal texture, as evolved during processing, has been examined as functions of both annealing effects and $\alpha_{2} \rightarrow \beta \rightarrow \alpha_{2}$ phase transformation cycle.

\section{Experimental}

The alloy with the nominal composition $\mathrm{Ti}-24 \mathrm{Al}-11 \mathrm{Nb}$ (at\%) was cast in the form of a pan cake. This material was suitably cut into small pieces and these were then subjected to hot rolling at three different temperatures, namely, $1173 \mathrm{~K}, 1293 \mathrm{~K}$ and $1373 \mathrm{~K}$, for rolling reductions ranging from $50 \%$ to $80 \%$. All the samples were quenched in water from the rolling temperature. The samples with the highest reduction were also furnace cooled from the respective rolling temperatures. Some pieces of the as-cast material were given a prior heat treatment for the equilibration of phases and then subjected to rolling at $1173 \mathrm{~K}$ by different amounts of reduction followed by water quenching.

The above as-rolled materials were subsequently annealed isochronally (for $1 \mathrm{~h}$ ) within the temperature range $1123 \mathrm{~K}-1293 \mathrm{~K}$ (at $\sim 50 \mathrm{~K}$ intervals) and also isothermally at $1173 \mathrm{~K}$ for time intervals ranging from $1 \mathrm{~h}-12 \mathrm{~h}$. In an alternative route of heat treatment, the differently processed as-rolled materials were heat treated at three different temperatures, corresponding to different phase fields, and then finally furnace cooled to room temperature. 
Texture study of the as-processed samples was undertaken using both the $\mathrm{X}$-ray pole figure as well as the orientation distribution function (ODF) methods. Each ODF was calculated from the data of 6 pole figures,

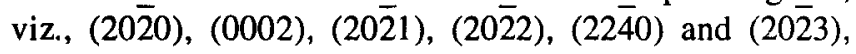
using the series expansion method of Bunge (1982) with $l_{\max }=32$.

\section{Results and discussion}

\subsection{Rolling texture}

The results of the present investigation indicate that the starting material, i.e. the as-cast alloy, possesses a strong basal texture and that this texture does not change significantly due to prolonged annealing at $1173 \mathrm{~K}$. Strong basal texture is also obtained when the starting material is rolled at $1173 \mathrm{~K}$, both in the water quenched and in furnace cooled conditions (figures $1 \mathrm{a}$ and $\mathrm{b}$ ). Among these two, the former gives rise to the sharpest basal texture.

The material, which was prior heat treated at $1173 \mathrm{~K}$ for a long time before rolling at $1173 \mathrm{~K}$ upto $80 \%$ reduction, exhibits an even sharper basal texture as compared to the samples mentioned above. In this case most of the orientations are concentrated along [0001] IND fibre. The degree of deformation during
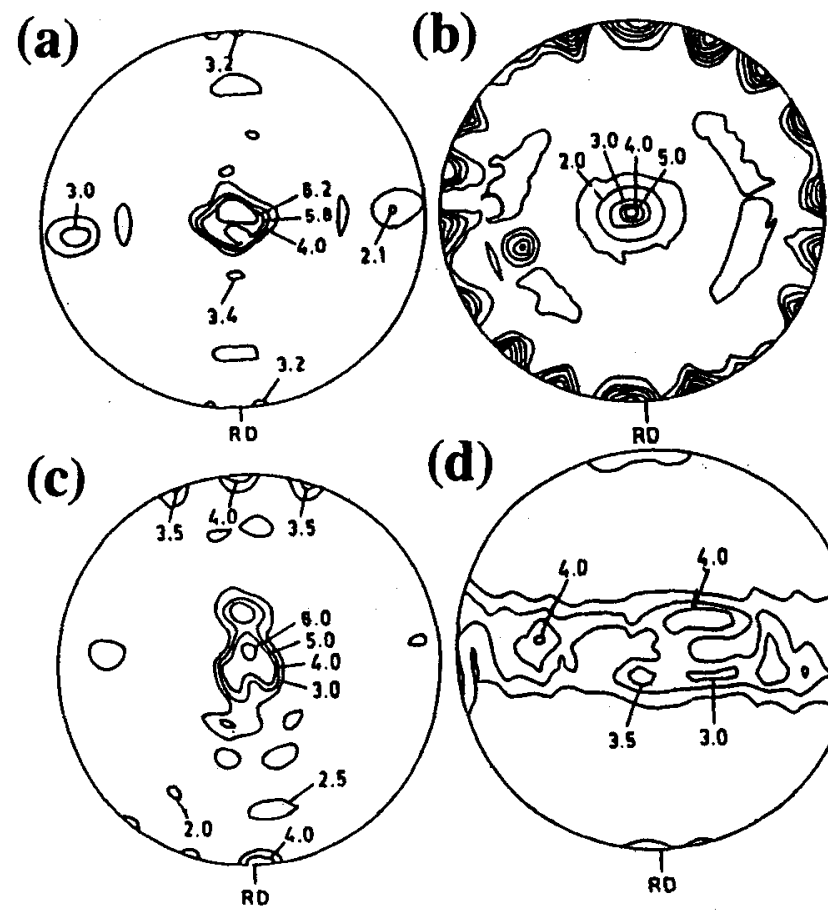

(d)

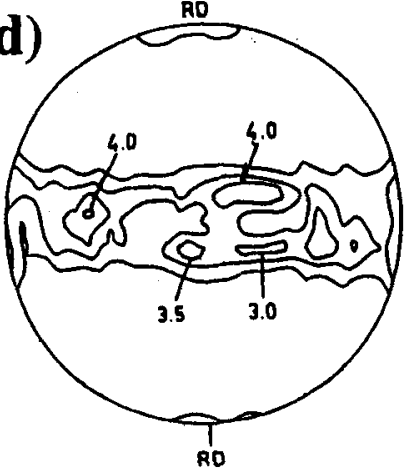

Figure 1. (0002) pole figures for the as-cast materials rolled at (a) $1173 \mathrm{~K}$ and water quenched, (b) $1173 \mathrm{~K}$ and furnace cooled, (c) $1293 \mathrm{~K}$ and water quenched and (d) $1293 \mathrm{~K}$ and furnace cooled. rolling also has a profound effect on the nature and extent of texturing. For example, the material rolled at $80 \%$ reduction at $1173 \mathrm{~K}$ shows a sharper basal texture than the one rolled to $50 \%$ reduction (figure 2).

Rolling at temperatures above $1173 \mathrm{~K}$ but below the $\beta$-transus ( $1373 \mathrm{~K} \pm 10 \mathrm{~K}$ ) is not favourable for obtaining good basal texture. Figure 1c shows the (0002) pole figure of a $1293 \mathrm{~K}$ rolled material to a reduction of $80 \%$. As it can be seen, the intensity of basal (0001)〈uvtw〉 orientations are only moderately strong. Furnace cooling of the same material gives rise to a relatively weak basal texture (figure $1 \mathrm{~d}$ ).

Hot rolling at temperatures above the $\beta$-transus followed by furnace cooling was carried out in order to have an idea about the transformation texture of secondary $\alpha_{2}$ resulting from the hot rolled $\beta$ phase. The temperature which was chosen for this purpose, namely $1373 \mathrm{~K}$, is just near the $\alpha_{2}+\beta / \beta$ phase boundary, where there is only a feeble chance of $\beta$ recrystallization during furnace (a) (i)

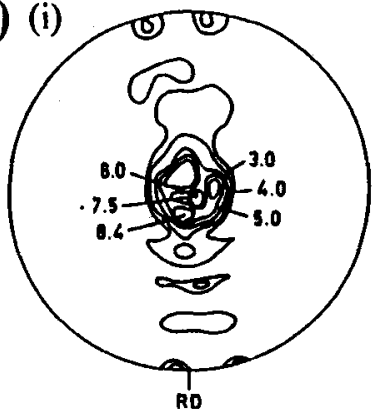

(b)

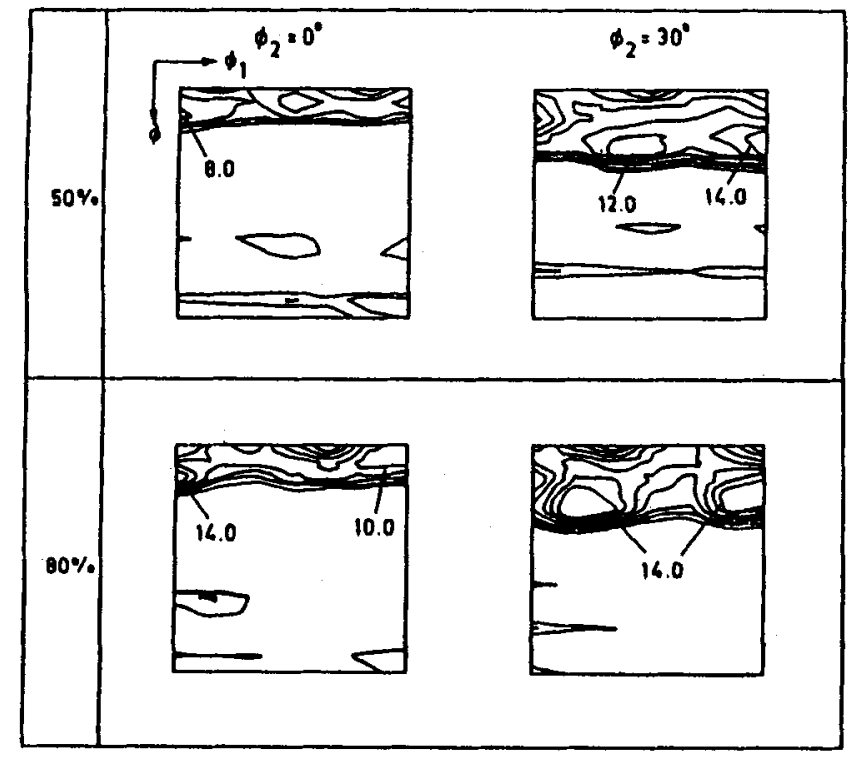

Figure 2. (a) (0002) pole figures for the material prior heat treated and rolled at $1173 \mathrm{~K}$ to the thickness reductions (i) $50 \%$ and (ii) $80 \%$ and (b) $\phi_{2}=0^{\circ}$ and $30^{\circ}$ sections of the ODFs for the same ( $50 \%$ and $80 \%$ rolled) materials. 
cooling. The $\beta$ rolling texture consists of $\{011\}\langle u v w\rangle$, $\{112\}\langle u v w\rangle,\{113\}\langle u v w\rangle$ and $\{223\}\langle u v w\rangle$ as the main components along with several other weaker ones. The resulting transformation textures are expected to be in accordance with the Burger's (1934) orientation relationship. Figures $3 a$ and $b$ represent the textures of the as-rolled and the rolled and furnace cooled materials. As it can be seen, the nature of texture evolved in transformed $\alpha_{2}$ is completely non basal. This has been attributed to variant selection during $\beta \rightarrow \alpha_{2}$ transformation. According to Fredericks (1973), in titanium or its alloys, when the transformation $\beta$ (b.c.c.) $\rightarrow \alpha$ (h.c.p.) takes place from deformed $\beta$, only one of the six variants of transformation is allowed. Therefore, only a few of the $\beta$ rolling components of texture will be favouring the transformation into $\alpha_{2}$ with basal orientation. Correspondingly, the resulting transformation texture is found to be away from basal and weak.

\subsection{Stability of rolling texture on annealing}

The stability of the rolling texture on post rolling heat treatment was studied by subjecting the rolled material to isochronal annealing for $1 \mathrm{~h}$ at temperatures $1123 \mathrm{~K}$, $1173 \mathrm{~K}, 1233 \mathrm{~K}$ and $1293 \mathrm{~K}$, followed by water quenching. These temperatures were chosen such that $\alpha_{2}$ remained the major phase, thus allowing the effect of heat treatment on the basal texture of $\alpha_{2}$ phase to be
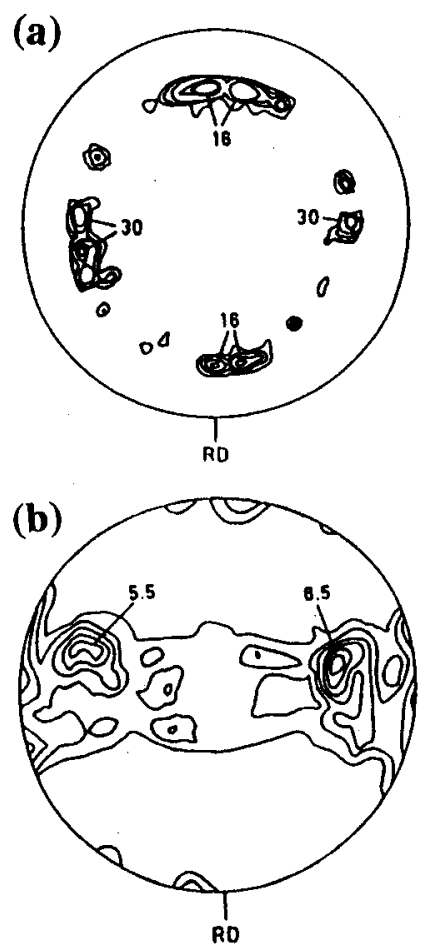

Figure 3. (a) (200) pole figure for the $1373 \mathrm{~K}$ rolled and water quenched material and (b) (0002) pole figure for the $1373 \mathrm{~K}$ rolled and furnace cooled material: examined. It was observed that on annealing at the lowest temperature, $1123 \mathrm{~K}$, where recrystallization of the $\alpha_{2}$ just begins, the basal texture weakens perceptibly and a number of other non basal orientations develop. However, it more or less regains its strength on annealing at $1173 \mathrm{~K}$ and $1233 \mathrm{~K}$. The basal texture again starts degrading at $1293 \mathrm{~K}$. On the basis of the above results, further isothermal annealing was performed at $1173 \mathrm{~K}$ over intervals of time ranging between $15 \mathrm{~min}-12 \mathrm{~h}$. The isothermally annealed samples also have shown initially a tendency for degradation of basal texture and evolution of non basal components for shorter annealing times and re-intensification of the basal texture after longer annealing times (figures $4 \mathrm{a}$ to $\mathrm{d}$ ). However, a relatively prolonged annealing for $12 \mathrm{~h}$ was found to be deleterious for the basal texture. The above observations on textural changes on isochronal as well as isothermal annealing are compatible with the common behaviour of annealing textures of h.c.p. metals and alloys where the rolling textures are retained after recrystallization (Dillamore and Roberts 1965).

\subsection{Stability of textures during $\alpha_{2} \rightarrow \beta \rightarrow \alpha_{2}$ transformation}

Finally, an attempt was also made in this investigation to examine the effect of $\alpha_{2} \rightarrow \beta \rightarrow \alpha_{2}$ transformation cycle on the stability of the basal as well as the non-basal
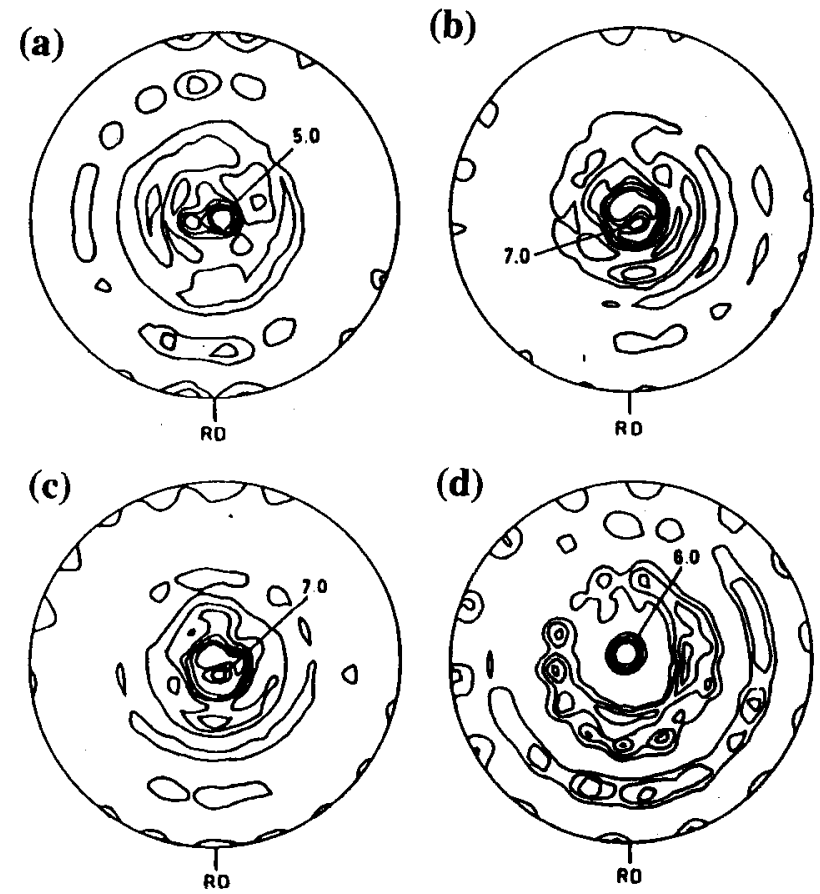

Figure 4. (0002) pole figures for the materials isothermally annealed at $1173 \mathrm{~K}$ for (a) $15 \mathrm{~min}$, (b) $30 \mathrm{~min}$, (c) $2 \mathrm{~h}$ and (d) $12 \mathrm{~h}$, 

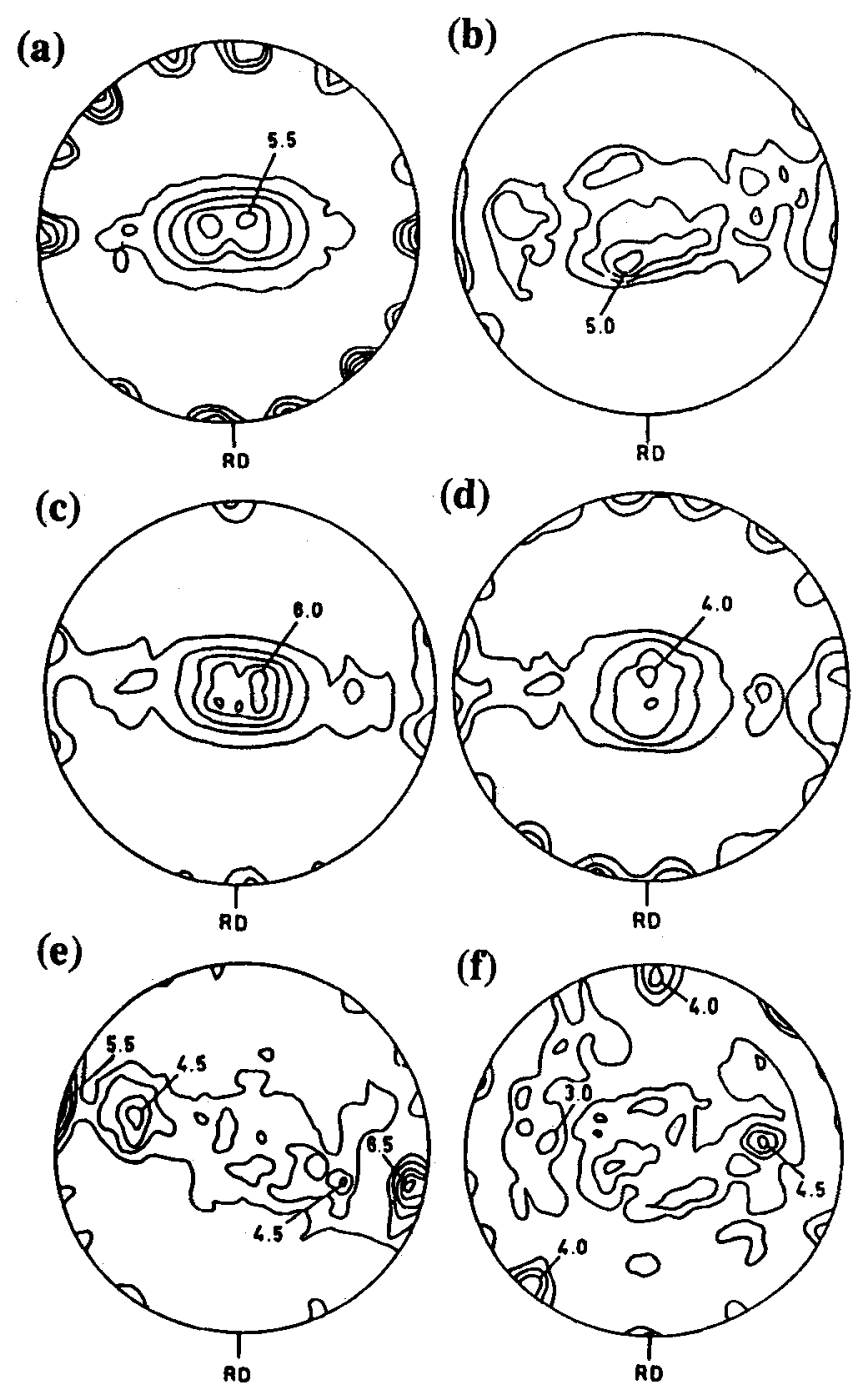

Figure 5. (0002) pole figures for the materials rolled at $1173 \mathrm{~K}$ (80\%, furnace cooled), subjected to heat treatments at (a) $1173 \mathrm{~K}$, (b) $1373 \mathrm{~K}$; rolled at $1293 \mathrm{~K}(80 \%$, furnace cooled), subjected to heat treatments at (c) $1173 \mathrm{~K}$, (d) $1373 \mathrm{~K}$; and rolled at $1373 \mathrm{~K}(80 \%$, furnace cooled) subjected to heat treatments at (e) $1173 \mathrm{~K}$, (f) $1373 \mathrm{~K}$.

components of texture. For this purpose samples showing three different types of textures-basal, weakly basal with non-basal components, and perfectly non-basal texture-were subjected to heat treatments in mostly the $\alpha_{2}$ phase field, equiproportional $\alpha_{2}+\beta$ phase field and the $\beta$ phase field followed by furnace cooling.

The texture results indicate that the material which already has a reasonably strong basal texture undergoes degradation on heat treatment in the $\alpha_{2}$ phase field for a long time (figure 5a). Heat treatment at the higher temperature of $1293 \mathrm{~K}$ degrades it further. After heat treatment above the $\beta$-transus, the material undergoes a phase transformation to $\beta$ followed by a second $\beta \rightarrow \alpha_{2}$ phase transformation during furnace cooling (figure $5 \mathrm{~b}$ ). This treatment has also been found to be detrimental to the preservation of the basal texture.

Similar heat treatments carried out on the material having a weak near basal texture and other non-basal components have shown results different from that of the material with starting basal texture. Heat treatment of this material at $1173 \mathrm{~K}$ seems to enhance the intensity of near basal texture (figure 5c). However, heat treating the same material at $1293 \mathrm{~K}$ causes a deterioration of the basal texture. Surprisingly, heat treatment at $1373 \mathrm{~K}$ caused significant improvement in the basal texture (figure 5d).

Heat treatment of the material with completely nonbasal starting texture, followed by furnace cooling does not seem to favour the formation of basal texture irrespective of the heat treatment temperature used (figures 5e and $\mathrm{f}$ ). These differences have been attributed to the differences in the nature of stress state of the starting $\alpha_{2}$ phase from which $\beta$ forms, to be re-transformed into secondary $\alpha_{2}$ during furnace cooling.

\section{Conclusions}

It is essential to have at least some intensity of the basal texture component in the starting material in order that a strong basal texture can be produced upon processing. Rolling at lower temperatures with high amounts of reduction usually favours the development of basal texture which remains reasonably stable even after complete recrystallization on heat treatment.

\section{Acknowledgements}

The authors are grateful to Dr D Banerjee, Director, DMRL, Hyderabad for his constant encouragement as well as for providing the texture measurement facility. We also thank Dr A K Singh for his cooperation and Dr A K Gogia and Mr T K Nandy for several useful discussions. The grant-in-aid from AR \& DB, Ministry of Defence, Government of India, is duly acknowledged.

\section{References}

Banerjee D 1994 Intermetallic compounds, principles and practice (eds) J H Westbrook and R L Fleischer (New York: John Wiley \& Sons), Vol. 2, p. 91

Bunge H J 1982 Texture analysis in materials science (London: Butterworths)

Burger W G 1934 Physica 1561

Dillamore I L and Roberts W T 1965 Metall. Rev. 10271

Fredericks S F 1973 AFML-TR-73-265 